\title{
Incidence of laryngeal complications associated with prolonged endotracheal intubation
}

\author{
Bansal A. ${ }^{1}$, Arora K. ${ }^{2}$ \\ ${ }^{1}$ Dr. Anshul Bansal, Associate Professor, ${ }^{2}$ Dr. Khushboo Arora, Junior Resident, both authors are affiliated with \\ Department of ENT and Head and Neck Surgery, Subharti Medical College, Meerut, U.P., India.
}

Corresponding Author: Dr. Anshul Bansal, Associate Professor, Department of ENT and Head and Neck Surgery, Subharti Medical College, Meerut, U.P., India. E-mail: dranshulparul@gmail.com, docparulbansal@gmail.com

\begin{abstract}
Introduction: Complications attributable to intubation increase morbidity and may increase the mortality rate. Aim: The aim of this study was to evaluate laryngeal lesions in patients after prolonged intubation $(>24 \mathrm{~h}$ ), to correlate these lesions with the variables involved in the process of intubation and to determine the risk factors. Materials and Methods: This is a prospective study of patients who were intubated for more than $24 \mathrm{~h}$ in ENT operation theatre and critical care unit. Patients underwent for laryngoscopy on the day of extubation, weekly after extubating for two weeks then monthly upto 6 months. Results: 66 patients were intubated in this study, laryngeal abnormalities were seen in most patients of all groups, on the day of extubation and only patients who undergone for prolonged intubation had abnormal finding a month after extubation. Conclusion: At the end of one-month laryngeal findings were influenced only by the duration of intubation.
\end{abstract}

Key words: Laryngeal injuries, Intubation, Laryngoscopy, Extubation

\section{Introduction}

Laryngeal injuries following intubation have a reported incidence from 63 to $94 \%$ and permanent sequelae are reported to be about 10 to $20 \%$ in world literature.

Common injuries following long term intubation can manifest in the form of erythema, ulceration, granulation, fibrous nodule, arytenoids dislocations, subglottic stenoses, recurrent laryngeal nerve paresis and vocal fold immobility [1-4]. After extubation laryngeal examination of such patients becomes necessary to assess the nature of airway injury. This study is based on data obtained from the endoscopic recognition of intubation trauma in larynx and associated structure with the objective to determine the frequency of short and long term complications.

\section{Materials and Methods}

This prospective study was conducted at CSS Hospital in Meerut. 66 cases were included in this study. Patients required planned or emergency intubation were included in the study. Patients were aged from15-60 years of age.

Manuscript received: $3^{\text {th }}$ October 2018

Reviewed: $12^{\text {th }}$ October 2018

Author Corrected: $18^{\text {th }}$ October 2018

Accepted for Publication: $24^{\text {th }}$ October 2018
Sample collection- Cases were selected randomly from two setup, a) from ENT operation theatre, where planned intubations were done during routine ENT surgeries, b) from medical ICU, where emergency intubation were done as a life saving measure for emergencies.

All patients were grouped into three. GroupN1:(n=22) included patients undergone for planned intubation for $<24$ h, Group N2: $(\mathbf{n = 2 2})$ included patients undergone for emergency intubation for $>24 \mathrm{~h}$ to $<7$ days and Group N3:(n=22) included patients intubated in emergency for $>7$ days.

Exclusion criteria- Patients with throat complains, history of gastro-esophageal reflux diseases/ thyroid surgery or addiction like tobacco, alcohol, smoking etc. were excluded from the study.

Complete laryngeal examination was done on the day of extubation and weekly for two weeks and monthly for 6 months in the form of indirect laryngoscopy, direct laryngoscopy or flexible fiberoptic laryngoscopy. 


\section{Original Research Article}

The association of laryngeal findings with intubation variables were evaluated. Various variables included nature of intubation (emergency or elective), route of intubation(oral/nasal), size of endotracheal tube, position of tube, tube characteristics, number of attempts/reintubation, use of stillete, ventilator/ ambu bag, cuff type/pressure during the intubation period, total period of intubation, post extubation tracheostomy and associated medical illness were studied. Informed consent was obtained from all subjects.

\section{Results}

66 patients were included in the study. Laryngeal abnormalities were seen in all the patients during examination on the day of extubation. On day of extubation congestion and change in voice was present in all the cases done.

Table 1 and 2 shows the various symptoms present in all three groups N1, N2 and N3on the day of extubation and one month after extubation. Table 3 and 4 shows various signs present on the day of extubation and after onemonthextubation in all three groups.

Table-1: Laryngeal Complications (Symptoms) First Day Post Extubation

\begin{tabular}{|l|c|c|c|}
\hline Symptoms & N1(n=22) & N2(n=22) & N3(n=22) \\
\hline Change in voice & $22(100 \%)$ & $22(100 \%)$ & $5(22.7 \%)$ \\
\hline Odynophonia & $10(45 \%)$ & $7(31.8 \%)$ & $4(18.1 \%)$ \\
\hline Aphonia & $2(9 \%)$ & $9(40.9 \%)$ & $7(31 . * \%)$ \\
\hline Vocal fatigue & $4(18.1 \%)$ & $8(36.6 \%)$ & $8(36.3 \%)$ \\
\hline Difficulty in respiration & 0 & $4(18.1 \%)$ & $4(18.1)$ \\
\hline Throat pain & $22(100 \%)$ & $7(31.8 \%)$ & - \\
\hline Cough & $5(22.7 \%)$ & $6(27.2 \%)$ & - \\
\hline Fever & $1(4.5 \%)$ & - & $4(18.1 \%)$ \\
\hline Odynophagia & $5(22.7 \%)$ & - & - \\
\hline Aspiration & - & - & \\
\hline Other complaint & - & & \\
\hline
\end{tabular}

Table-2: Laryngeal Complications (Symptoms)-One Month Post Extubation

\begin{tabular}{|l|c|c|c|}
\hline Symptoms & N1 $(\mathbf{n}=\mathbf{2 2})$ & $\mathbf{N 2}(\mathbf{n}=\mathbf{2 2})$ & $\mathbf{N 3}(\mathbf{n}=\mathbf{2 2})$ \\
\hline Change in voice & 0 & $2(9 \%)$ & $12(54.5 \%)$ \\
\hline Odynophonia & 0 & 0 & $1(4.5 \%)$ \\
\hline Aphonia & 0 & $1(4.5 \%)$ & $4(18.1 \%)$ \\
\hline Vocal fatique & 0 & 0 & $1(4.5 \%)$ \\
\hline Difficulty in respiration & 0 & $2(9 \%)$ & $4(18.1 \%)$ \\
\hline Throat pain & 0 & 0 & $4(18.1 \%)$ \\
\hline Cough & 0 & 0 & 0 \\
\hline Fever & 0 & 0 & $1(4.5 \%)$ \\
\hline Odynophagia & 0 & 0 & - \\
\hline Aspiration & 0 & 0 & 0 \\
\hline Other complaint & 0 & 0 & 0 \\
\hline
\end{tabular}

One month post extubating, in group N1 none had laryngeal complications but in group N2, 2 patients (9.09\%) patients had laryngeal complications, whereas in group N3, 8 patients $(36.3 \%)$ patients had laryngeal complications.

One month after extubation no change in the voice was existing in patients of $\mathrm{N} 1$ group but was present in 2 patients (9.09\%) of N2 group and 12 patients $(54.54 \%)$ of N3 group. 
Table-3: Laryngeal Complications (Signs): First Day Post Extubation

\begin{tabular}{|c|c|c|c|}
\hline Signs & N1 & N2 & N3 \\
\hline Congestion & $22(100 \%)$ & $13(59 \%)$ & $7(31.8 \%)$ \\
\hline Edema & $10(45.4 \%)$ & $11(50 \%)$ & $8(36.3 \%)$ \\
\hline granulation & $6(27.2 \%)$ & $9(40.9 \%)$ & $8(36.3 \%)$ \\
\hline Ulceration & $6(27.2 \%)$ & $8(36.3 \%)$ & $6(27.2 \%)$ \\
\hline Intubation granuloma & 0 & 0 & 0 \\
\hline Fibrous nodule & 0 & 0 & 0 \\
\hline Interarytenoid adhesion & 0 & 0 & 0 \\
\hline Healed furrow & 0 & 0 & 0 \\
\hline Posterior glottis stenosis & 0 & 0 & 0 \\
\hline Subglottic stenosis & 0 & 0 & $3(13.6 \%)$ \\
\hline URLNP & 0 & $1(4.5 \%)$ & 0 \\
\hline BRLNP & 0 & 0 & $2(9 \%)$ \\
\hline Arytenoids dislocation & 0 & 0 & 0 \\
\hline Arytenoids fixation & 0 & 0 & 0 \\
\hline
\end{tabular}

Table-4: Laryngeal Complications (Signs): One Month Post Extubation

\begin{tabular}{|c|c|c|c|}
\hline Signs & N1 $(n=22)$ & $\mathrm{N} 2(\mathrm{n}=22)$ & $\mathrm{N} 3(\mathrm{n}=22)$ \\
\hline Congestion & 0 & 0 & 0 \\
\hline Edema & 0 & 0 & 0 \\
\hline Ulceration & 0 & $2(9 \%)$ & $2(9 \%)$ \\
\hline Granulation & 0 & 0 & 0 \\
\hline Intubation granuloma & 0 & 0 & $2(9 \%)$ \\
\hline Fibrous nodule & 0 & $1(4.5 \%)$ & $2(9 \%)$ \\
\hline Interarytenoid adhesion & 0 & 0 & $1(4.5 \%)$ \\
\hline Healed furrow & 0 & 0 & 0 \\
\hline Posterior glottis stenosis & 0 & 0 & 0 \\
\hline Subglottic stenosis & 0 & 0 & $1(4.5 \%)$ \\
\hline URLNP & 0 & $1(4.5 \%)$ & $3(13.6 \%)$ \\
\hline BRLNP & 0 & 0 & $1(4.5 \%)$ \\
\hline Arytenoids dislocation & 0 & 0 & $2(9 \%)$ \\
\hline Arytenoids fixation & 0 & 0 & 0 \\
\hline
\end{tabular}

In group N3, post extubation changes after one month were - Granulation was present in 2 patients (9\%), granuloma in 2 patients $(9 \% \%)$, interarytenoid adhesion in 1 patient $(4.5 \% \%)$, subglottic stenosis in 1 patient $(4.5 \%)$, unilateral recurrent laryngeal nerve paresis in 3 patients (13.6\%) and bilateral recurrent laryngeal nerve paresis in 1 patient (9\%). Among these changes most frequent change present one month post extubation was unilateral recurrent laryngeal nerve paresis.

Table-5: Laryngeal complications in relation to duration of intubation

\begin{tabular}{|c|c|}
\hline Patients Subgroup & Laryngeal sequlae after one month \\
\hline $\mathrm{N} 1<24 \mathrm{~h}(\mathrm{n}=22)$ & $\mathrm{O}(0 \%)$ \\
\hline $\mathrm{N} 2<24 \mathrm{~h}>7$ days $(\mathrm{n}=22)$ & $2(9 \%)$ \\
\hline $\mathrm{N} 3>7$ days $(\mathrm{n}=22)$ & $11(36.3 \%)$ \\
\hline
\end{tabular}


Table-6: Laryngeal Complications related to Tube Used

\begin{tabular}{|l|c|c|c|}
\hline Sequalae & Portex (high volume low pressure cuff) & Size (mm) & Tube motion \\
\hline Intubation granuloma & + & 9 & + \\
\hline Vocal cord paresis & + & 8.5 & + \\
\hline Arytenoids subluxation & + & 9 & + \\
\hline Subglottic stenosis(f) & + & 8.5 & + \\
\hline Fibrous nodule & + & 9 & + \\
\hline
\end{tabular}

Table-7: Number of Attempts/ Reintubation versus Laryngeal Sequlae

\begin{tabular}{|l|c|c|}
\hline Sequalae & Number of patient & History of Reintubation \\
\hline Intubation granuloma & 1 & + \\
\hline Fibrous nodule (m) & 1 & + \\
\hline Vocal cord paresis (f) & 2 & + \\
\hline Arytenoids subluxation (m) & 2 & + \\
\hline Subglottic stenosis (f) & 2 & - \\
\hline
\end{tabular}

Table 5 to 7 shows various variables and their association with the laryngeal sequelae in all three groups. Analysis of the intubation variables showed oral route of intubation, use of portex tube, lateral position of tube during intubation,more number of attempts, use of stellate, CMV, reintubation were associated with post extubation laryngeal sequelae.

\section{Discussion}

In N1 group, the most common symptom was, throat pain and change in voice signifying the acute complications of intubation.In N2 and N3 groups also the most common symptom was change in voice $(100 \%)$, signifying the effect of duration of intubation on the voice box. Results of our study are in accordance with the study done by Alessiet alwho reported hoarseness in $96 \%$ cases in his study [5].

In our study,Odynophagia was not seen in patients of group N2 and group N3 but was present in 5 patients (22.7\%) of group N1, who were intubated for less than 24hours (group N1).

Those patients were relieved completely after 15 days. In a study done by Alessiet alreported odynophagia in 22 patients $(76 \%)$ out of his 29 patients [5].

In present study 6 patients had aspiration out of $66(9 \%)$. Alessiet alin his study reported aspiration in 10 out of 29 patients $(34 \%)$ [5]. In present study 8 patients had complain of post intubation stridor $(12.1 \%)$ out of which 5 (7.5\%) got tracheostomised.

In group N2, Out of 22 patients 13 (59\%) had congestion of the vocal cords, 8 patients $(36.3 \%)$ had ulceration involving vocal processes of both arytenoids and inter-arytenoid region, but after a month the lesions responded well to medical therapy. Alessiet alhas reported ulceration in 23 patients out of 29 (79\%) [5].

In group N3, 2patients (9\%) had intubation granuloma formation after one month despite medical therapy. Alessiet al reported intubation granuloma in 5 patients out of $22(22.7 \%)$, who were having ulceration previously [2].

Pontes et al also reported intubation granuloma in $22.7 \%$ of the cases. However incidence of granuloma varies from 1:800 to $1: 30$ as reported in world literature [6].

2patients (9\%) of group N3 had a fibrous nodule on right true vocal cord at the junction of anterior $1 / 3^{\text {rd }}$ and posterior $2 / 3^{\text {rd }}$.

One patient was given voice therapy and improved drastically. One patient had a nodule on left true vocal cord and responded to conservative management.

Total 3 cases (13.6\%) of group N3 were identified with unilateral recurrent laryngeal nerve paresis, out of which one recovered with conservative management where as two had to be tracheostomised, out of which one was successfully decannulated and the other one waskept on follow up. 


\section{Original Research Article}

One case from group N3 was reported with bilateral recurrent laryngeal nerve paresis (4.5\%) and wasmanaged conservatively as she had no significant difficulty in respiration.

One case fromN3 group, subglottic stenosis was detected after intubation for $>12$ days. Spruance $\mathrm{J}$ S et alfound that intubation less than 7 days leads to reversible changes in larynx and subglottic areas, but when this time was increased beyond 14 days, the changes were irreversible [7].

Whited et alreported $2 \%$ stenosis in patients with intubation between 3 and 5 days and it was increased to $5 \%$ when intubation period was between six and ten days [8].

Present study reported no permanent laryngeal injury following intubation $<24$ hours after one month of extubation. Patients with intubation $>24$ hoursto $<7$ day (group N2) were presented with $9 \%$ complications. Incidence of laryngeal trauma in patients with intubation $>7$ days was found to be $36.3 \%$.

The presence of laryngeal complications at the end of one month after extubation was highly related only to the duration of intubation. This is in accordance with the studies done by Whited RE and Kastanos Net al $[8,9]$.

Nasal intubation was done mainly in N1 and N2 group. Only nasal bleeding wasseen in 4 patients, which stopped on its own and no surgical intervention was required. Gaynor EB et al proposed more frequent use of nasal intubation to reduce laryngeal trauma as compared to oral intubation [10].

However Brandwein et al suggested that the length of intubation tube should also be considered if a nasotracheal intubation is done with a tube intended for orotracheal use, the increased distance traversed by the tube will result in the balloon cuff being situated just beneath the vocal cords [11].

Anatomically this may be a setup for compression injury to recurrent laryngeal nerve.Probably the most important factor in producing a traumatic injury to larynx and trachea is the pressure applied by the tube to the underlying structures.

In all the patients with laryngeal sequelae, low pressurehigh volume cuff was used there by indicating the importance of duration of intubation, which played a major role in causing them.

\section{Conclusion}

Initial laryngeal injuries are quite common but most of the patients tend to recover, as these are superficial mucosal injuries. Thepatients, who had undergone for intubation more than 7 days had permanent laryngeal complications. Thus one month post extubation, duration of intubation was the only predictor of post extubation laryngeal sequelae.

This study also showed that laryngeal injuries on the day of extubation were associated with larger tube size, emergency intubation and longer duration of intubation. Use of appropriate tube size and monitoring of duration of intubation is of paramount importance.

\section{Funding: Nil, Conflict of interest: Nil Permission from IRB: Yes}

\section{References}

1. Rieger A, Hass I, Gross M, et al. [Intubation trauma of the larynx--a literature review with special reference to arytenoid cartilage dislocation]. Anasthesiol Intensiv med Notfallmed Schmerzther. 1996 Jun;31(5):281-7. DOI:10.1055/s-2007-995921

2. Obrebowski A, Wojnowski W. Hoarseness resulting from post-intubation arytenoid cartilage subluxation in an 11-year-old girl. Otolaryngol Pol 1998;52:223-6.

3. Lundy DS, Casiano RR, Shatz D, et al. Laryngeal injuries after short- versus long-term intubation. J Voice. 1998 Sep;12(3):360-5.

4. Santos PM, Afrassiabi A, Weymuller EA Jr. et al. Risk factors associated with prolonged intubation and laryngeal injury. Otolaryngol Head Neck Surg. 1994 Oct;111(4):453-9.

5. Alessi DM, Hanson DG, Berci G. Bedside videolaryngoscopic assessment of intubation trauma. Annals of Otology Rhinology and Laryngology 1989;98:586-90.

6. Pontes P AL, De Biase N G, Gadelha E C. Clinical evolution of laryngeal granulomas: treatment and prognosis. Laryngoscope 1999;109:289-94.

7. Supance JS, Reilly JS, Doyle WJ, et al. Acquired subglottic stenosis following prolonged endotracheal intubation. A canine model. Arch Otolaryngol. 1982 Nov;108(11):727-31. 


\section{Original Research Article}

8. Whited RE. Posterior commissure stenosis post longterm intubation. Laryngoscope. 1983 Oct;93(10):1314-8.

9. Kastanos N, Estopá Miró R, Marín Perez A, Xaubet Mir A, Agustí-Vidal A. Laryngotracheal injury due to endotracheal intubation: incidence, evolution, and predisposing factors. A prospective long-term study. Crit Care Med. 1983 May;11(5):362-7.
10. Gaynor EB, Greenberg SB. Untoward sequelae of prolonged intubation. Laryngoscope. 1985 Dec;95(12):1461-7.

11. Brandwein M, Abramson AL, Shikowitz MJ. Bilateral vocal cord paralysis following endotracheal intubation. Arch Otolaryngol Head Neck Surg. 1986 Aug;112(8):877-82.

\section{How to cite this article?}

Bansal A., Arora K. Incidence of laryngeal complications associated with prolonged endotracheal intubation. Trop J Ophthalmol Otolaryngol.2018;3(4):69-74.doi: 10.17511/jooo.2018.i04.02 